\title{
of the meeting on
}

\section{Coordination of FAO/NGOs autumn 2003 Seed and Fertilizer Distribution}

Chairperson: Mr. Antonio Di Leonardo, FAO Emergency Coordinator for Afghanistan.

Time and Date: 10 am Thursday 10 July 2003.

Venue: $\quad$ FAO Office, Darul-Aman, Kabul, Afghanistan.

Participants: $\quad$ FAO, NGOs and ISE. (List is attached)

Agenda: $\quad$-Priority areas for autumn 2003 distribution;

-FAO/ECU recommendation for reimbursement collects;

-NGOs experiences;

$-\mathrm{AOB}$.

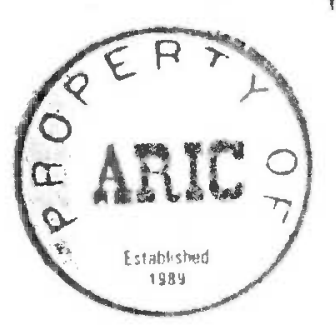

\section{Introduction}

Antonio Di Leonardo thanked the participants for coming and introduced himself as the new FAO Emergency Coordinator in Kabul, as Mona Chaya, the previous coordinator, has departed.

\section{Presentation: FAO seed and fertilizer distribution programme for autumn 2003}

Mr Javier Escobedo, FAO Senior Agronomist, led the presentation, which included a PowerPoint slide show. The presentation is attached.

\section{Discussion following presentation}

Mr Di Leonardo reiterated that the priority beneficiaries of the upcoming autumn distribution by FAO are the most vulnerable, especially returnees. The time frame for the distribution is:

- Soon after mid-August: The first deliveries will be made to NGO warehouses in priority regions in terms of the agricultural calendar.

- 15 October: This is the target date for all deliveries to be made to NGO warehouses.

The distribution will include $1020 \mathrm{MT}$ of rain-fed wheat seed varieties and $1680 \mathrm{MT}$ of irrigated wheat seed varieties. The composition of the kit per beneficiary will remain the same as last year:

$50 \mathrm{~kg}$ of wheat seed (rain-fed varieties) and $25 \mathrm{~kg}$ of DAP or $50 \mathrm{~kg}$ of wheat seed (irrigated varieties), $50 \mathrm{~kg}$ of DAP and $50 \mathrm{~kg}$ of urea. These quantities should enable each family beneficiary to cultivate about 0.35 ha (irrigated land) or 0.6 ha (rain-fed land).

What percentage of returnees have access to land " asked by Osmanzai, CYMMIT

Mr Di Leonardo explained that FAO, in collaboration with UNHCR and implementing partner NGOs, will seek to ensure that returnees who are recipients of the FAO distribution will have access to land. In particular, it will be the responsibility of implementing partner NGOs to ensure that the beneficiary criteria established by FAO are adhered to.

What is the definition of vitnerable people "? asked by Ashraf Ali. OXFAM

Mr Di Leonardo reiterated that beneficiaries would be selected based on the criteria developed for the previous distribution programmes. In general, vulnerable groups include the returnees, disabled, widows, female-headed households, elderly headed household etc. 
Mr. Baroukzai, representative of the French Embassy informed that 15 varieties of seed have been tested with NGOs and the Ministry of Agriculture and Animal Husbandry (MAAH). Following the results of the tests, a certain amount of seed will be distributed in 2003. The regions to receive the seed will be determined according to the results of the tests and the needs identified. Distribution will be undertaken through $\mathrm{MAAH}$ extension services.

$\mathrm{Mr} \mathrm{Di}$ Leonardo recommended that the information on quantities and areas covered is know it should be shared so that coordination could be implemented and overlaps avoided.

He noted that different seed programmes are being undertaken by different actors, with some mixing seed production with seed distribution. Mr Di Leonardo mentioned that Mercy Corps has expressed concern about how to integrate these two operations at the same time. When possible, the production and the distribution for relief should be conducted separately. As the beneficiaries of the seed distributions are those who cannot afford to by seed, there should not be any competition between the two programmes. This is mainly relying on how the Implementing Partners will stick to the criteria for the selection of beneficiaries.

Mr Di Leonardo also addressed the concern that $50 \mathrm{~kg}$ of seed per beneficiary is too much, and that the quantity could be reduced in order to increase the total number of beneficiaries. He noted that FAO already targets smallholders usually with between .35 ha (irrigated) and .5 ha (rain-fed) of land. A minimum of $50 \mathrm{~kg}$ of seed is recommended in order to maximize the food security of beneficiaries and also to allow them to produce surplus for sale and stock. Though the exceptional yields this past year may warrant reducing the quantity of seed per beneficiary and thus increasing the total number of beneficiaries, there is no guarantee that the yields from the forthcoming planting season will be as high.

\section{Increasing price of wheat seed}

The representative of the Swedish Committee worried about the increasing price of wheat seed. He suggested that this is due to many farmers being contracted to produce seed for distribution programmes. He suggested that the price of seed be somehow regulated.

Mr Di Leonardo informed that a National Seed Committee has been recently formed under the MAAH and with assistance from FAO. One of the mandates of the committee could be to regulate the price of wheat seed. $\mathrm{Mr}$ Di Leonardo also noted that FAO purchases from recognized private seed enterprises through standard tendering procedures. The selected suppliers can therefore plan for the production and procurement, so there is little influence on the price.

Mr. Di Leonardo concluded that the emergency seed and fertilizer distribution programme should not disturb the rule and regulation of regular and development seed programmes.

\section{Presentation: Reimbursement of distributed emergency inputs}

Mr Di Leonardo led the presentation, which included a PowerPoint slide show. The presentation is attached

\section{Discussion following the presentation}

One of the concerns raised following the presentation was that the shuras, or village associations, involved in the reimbursement schemes, in managing the capital collected, and in devising ways to use the capita, are not always reliable or transparent. It was suggested that impact studies be undertaken to evaluate the reimbursement schemes. These studies would record what capital is collected (cash, wheat grain), what percentage of beneficiaries contribute, how the capital is used, which NGOs are successful in implementing the reimbursement schemes, which NGOs use the collected reimbursement for their own community programmes, etc.

A representative from Euronaid suggested that a strategy be developed for reimbursement schemes and use of capital collected, particularly with regard to collected seed. Mr Di Leonardo explained that FAO does not recommend redistributing collected seed, as quality can not be assured. The strategy of these distributions is to ensure food security of target farmers, and not seed production. 
A representative of IRC asked for the reimbursement plan for next year. Mr Di Leonardo noted that the same framework used last year would be applied this year. It is up to the NGO to decide what reimbursement system is best, what should be collected, and to ensure that the participating shura is reliable and held accountable. Mr Di Leonardo also mentioned that there is financial incentive (job creation, operating costs) for all parties (shuras, NGOs) involved in implementing the reimbursement schemes. FAO, however, does not ask for compensation at any stage of the reimbursement schemes.

A representative of the Swedish Committee was sceptical that NGOs would be able to achieve the target reimbursement rate established by FAO. FAO has indicated that the ideal rate would be $80 \%$ participation from beneficiaries farming on irrigated land and 50\% participation from beneficiaries farming on rain-fed land.

Mr. Ashraf Ali from OXFAM also rose that how FAO calculated the $80 \%$ and $50 \%$ rates for reimbursement for irrigated and rain fed respectively. Mr. Antonio Di Leonardo stated that the calculation based on predicted constraints and achievements.

Mr Di Leonardo concluded the discussion by stating that NGOs should try to implement reimbursement schemes. As most of the reimbursement collected is in the form of wheat grain, this promotes diffusion of seed over a wide area through exchanges. The NGOs could also take advantage of the very good harvest expected this year and of the possible increased wheat sales by farmers to initiate creation of collective wheat storage and marketing. 
$\underline{\text { List of participants }}$

\begin{tabular}{|c|c|c|c|}
\hline Name & Organization & Telephone & Email \\
\hline 1. Ms. A Ramos & IRC & 070292264 & afgagri@theirc.org \\
\hline 2. Mr. Zundi Gul Zamani & IRC & 070278162 & irccentral@uuplus.com \\
\hline 3. Mr.Faizullah & ISE & & \\
\hline 4. Mr.M.T. Maqsood & PRB & 2200012 & \\
\hline 5. Mr.Gh. Faruq & PRB & 2200012 & \\
\hline 6. Mr.Aziz Osmanzai & GAA (Kabul) & 2201509 & aosmanzai@yahoo.com \\
\hline 7. Mr.Khan Mohammad & GAA (Saripul) & & \\
\hline 8. Mr.Zalmai Hameedi & PWJ & 070274618 & pwjkabul@tkk.att.ne.jp \\
\hline 9. $\quad$ Mr.Mehry & HAFO & 070279752 & hafokabul@yahoo.com \\
\hline 10. Mr.S.A. Sahrayee & SCA & 070299303 & rdtsu@brain.net.pk \\
\hline 11. Mr.Jordan Ramacciato & FAO & & jordan.ramacciato@af.fao.org \\
\hline 12. Ms.Farida Lamay & $\mathrm{FAO}$ & 070292472 & farida.lamay@af.fao.org \\
\hline 13. Mr.F. Baroukzai & French Embassy & 070278271 & farouq.baroukzai@diplomatie.gouv.fr \\
\hline 14. Ms.Sabine Verderber & World Vision & 070279561 & Sabine_verderber@wvi.org \\
\hline 15. MrSarvesh Paliwal & CIMMYT & & s.paliwal@cgiar.org \\
\hline 16. Mr.Mahmood Osmanzai & CIMMYT & 070282083 & m.osmanzai@cgiar.org \\
\hline 17. Mr.Khalilullah Rahmani & Euron Aid & $07 \overline{0280881}$ & rahmani_e@yahoo.com \\
\hline 18. Mr.Eruh Bertziea & GAA & & Dwhhbentrien@les_raisting.de \\
\hline 19. Mr.Ashraf Ali & Oxfam & 070281733 & maali@oxfam.org.uk \\
\hline 20. Ms.Anna Minkiewicz & Solidarites & & agroafg@immarsat.francetelecom.fr \\
\hline 21. Mr.Sanjar & AKDN & 2301189 & \\
\hline 22. Dr.Samin & AAD & 570230 & hoadid@brain.net.pk \\
\hline 23. Mr.Zla-u-Rahman & $\mathrm{FAO}$ & 070277471 & zia.rahamn@af.fao.org \\
\hline 24. Mr. Antonio Di Leonardo & $\mathrm{FAO}$ & 070285266 & \\
\hline 25. Mr. Javier Escobedo & FAO & 070299032 & \\
\hline
\end{tabular}

